\title{
Polymerization of Cyclic Acetals by a Free Radical Initiator, Perfluorodibenzoyl Peroxide in the Presence of Oxygen
}

\author{
Yu Yang, František Mikeš, Yoshiyuki Okamoto* \\ Polymer Research Institute, Polytechnic University, \\ Six MetroTech Center, Brooklyn, NY11201
}

Email: yangyu_doc@yahoo.com; yokamoto@poly.edu

\section{Supporting Information}

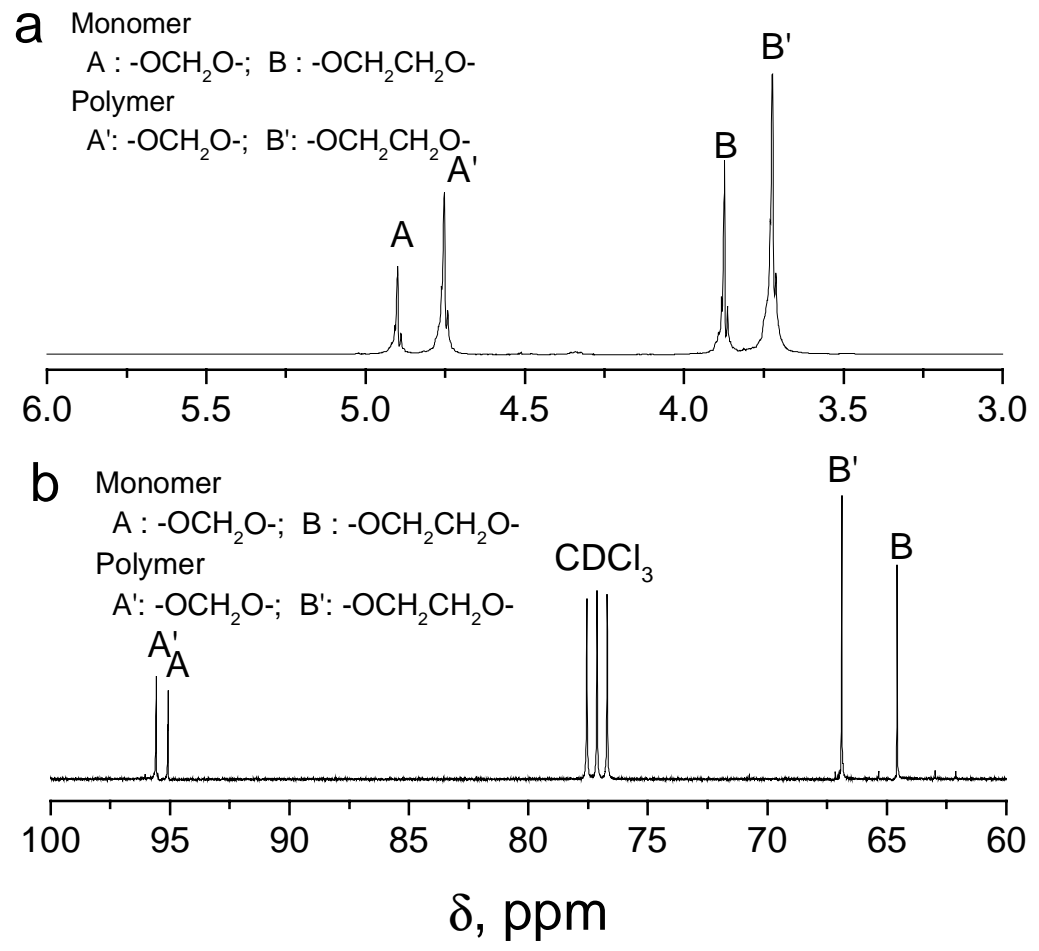

Figure S1. ${ }^{1} \mathrm{H}$ (a) and ${ }^{13} \mathrm{C}$ NMR (b) spectra of one typical polymerization mixture. Polymerization condition: 1,3-dioxolane (17.0 mmol), perfluorodibenzoyl peroxide (0.048 mmol), $\mathrm{O}_{2}(0.18 \mathrm{mmol}), 60{ }^{\circ} \mathrm{C}$. 


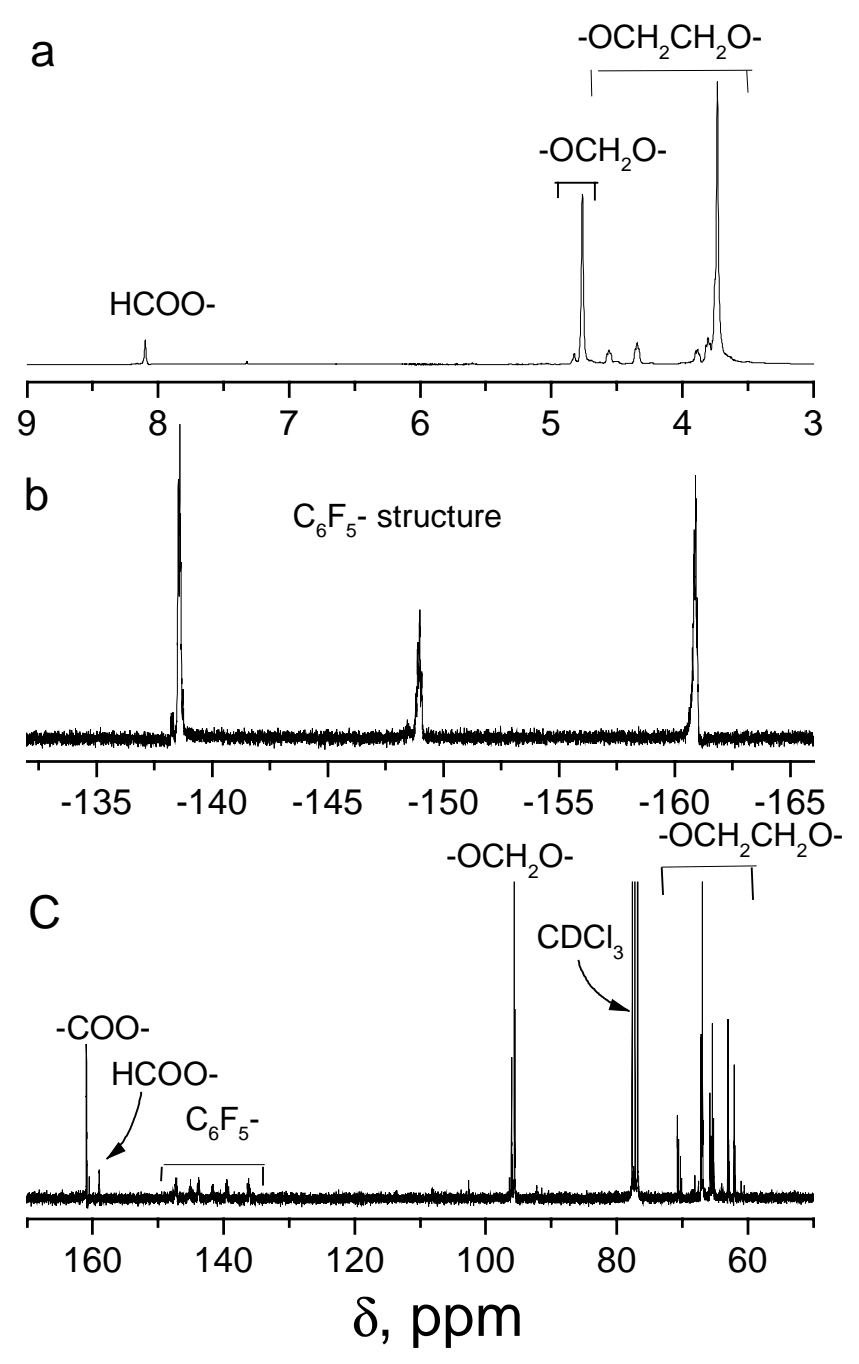

Figure S2. ${ }^{1} \mathrm{H}(\mathrm{a}),{ }^{19} \mathrm{~F}(\mathrm{~b})$ and ${ }^{13} \mathrm{C}$ NMR (C) spectra of the oligomer. Polymerization condition: 1,3-dioxolane (6.4 mmol), perfluorodibenzoyl peroxide $(0.8 \mathrm{mmol})$ and $\mathrm{O}_{2}$ $(0.18 \mathrm{mmol})$ at $80^{\circ} \mathrm{C}$ for 4 days 


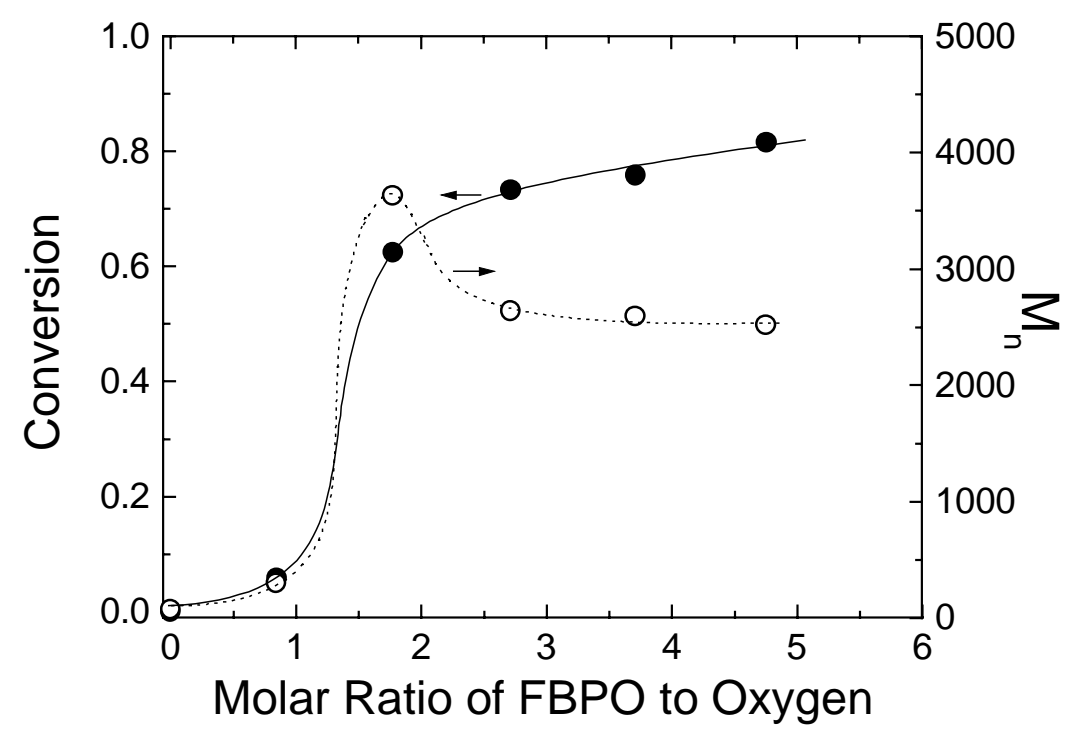

Figure S3. Dependence of conversion and the number-average molecular weight $\left(M_{n}\right)$ of polymer on molar ratio of perfluorodibenzoyl peroxide (FBPO) to $\mathrm{O}_{2}$. Polymerization conditions: 1,3 -dioxolane $(17 \mathrm{mmol}), \mathrm{O}_{2}(0.03 \mathrm{mmol}), 80{ }^{\circ} \mathrm{C}$ and 14 days. 


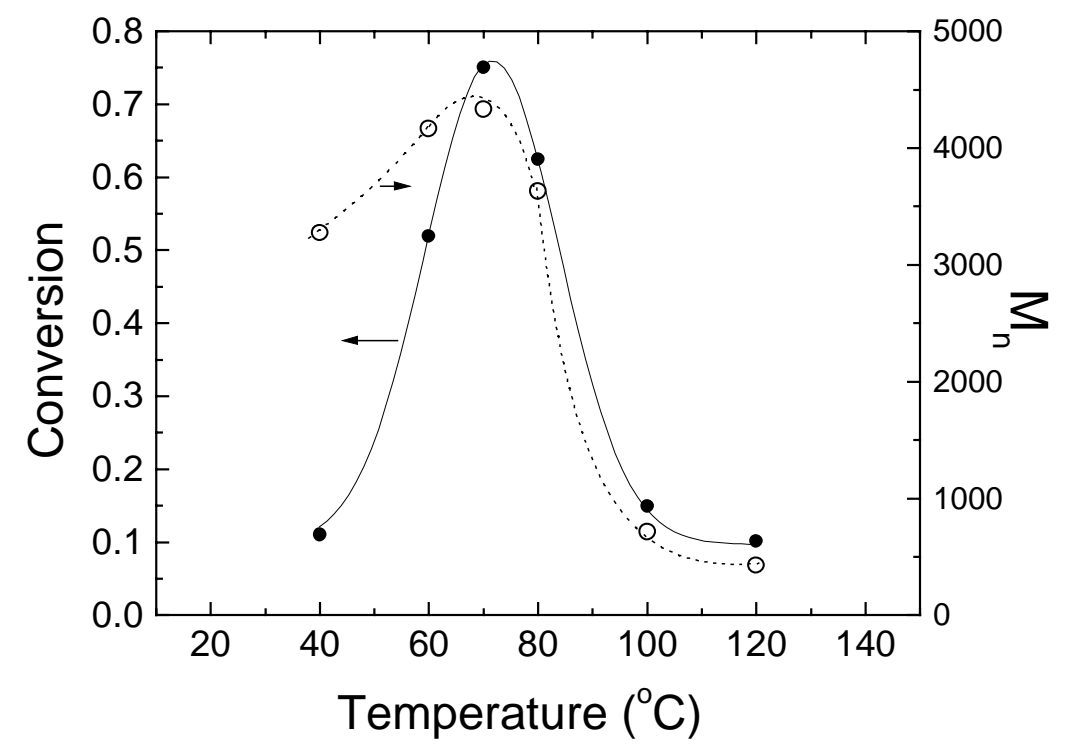

Figure S4. Dependence of conversion and the number-average molecular weight $\left(\mathbf{M}_{n}\right)$ of polymer on polymerization temperature. Polymerization condition: 1,3-dioxolane (17 mmol), perfluorodibenzoyl peroxide $(0.056 \mathrm{mmol}), \mathrm{O}_{2}(0.03 \mathrm{mmol})$, and 14 days. 